\title{
Regulation of polyethylene glycol 400 intestinal permeability by endogenous and exogenous prostanoids. Influence of non-steroidal anti-inflammatory drugs
}

\author{
P Krugliak, D Hollander, K Le, T Ma, V D Dadufalza, K D Katz
}

\begin{abstract}
Polyethylene glycol 400 (PEG 400) is a clinically useful intestinal permeability probe whose rate of intestinal permeation is influenced in part by solvent drag. As mucosal prostanoids are increased in inflammatory bowel disease and affect water transport we examined the possible relationship between prostaglandin $\mathbf{E}_{2}$ $\left(\mathrm{PGE}_{2}\right)$ and the inhibitors of endogenous prostaglandins - the non-steroidal anti-inflammatory drugs (NSAIDS) - on PEG 400 absorption in vivo using segmental perfusion of rat small intestine. We found that the addition of exogenous $\mathrm{PGE}_{2}$ in concentrations of $0.5,1.0$, and $1.5 \mu \mathrm{g} / \mathrm{ml}$ significantly $(\mathbf{p}<0.01)$ decreased PEG 400 and water absorption. Addition of $5 \mathrm{mmol} / \mathrm{l}$ of the cyclooxygenase inhibitors acetylsalicylic acid (ASA) or indomethacin in concentrations 2.5 or $5.0 \mathrm{mmol} / 1$ to the perfusate significantly $(p<0.01)$ increased PEG 400 and water absorption. The simultaneous addition of $1.0 \mu \mathrm{g} / \mathrm{ml}$ of exogenous $\mathrm{PGE}_{2}$ to the perfusate with $5 \mathrm{mmol} / \mathrm{l}$ of $\mathrm{ASA}$ or with 2.5 $\mathrm{mmol} / \mathrm{l}$ of indomethacin reversed the increase of PEG 400 and water transport $(p<0.01)$. There were no differences in PEG 400 and water absorption when $\mathrm{PGE}_{2}$ was given alone or in combination with ASA or indomethacin. This study suggests that endogenous or exogenous prostanoids play an important role in the regulation of PEG 400 permeation. PGE $_{2}$ and NSAIDS modify PEG $\mathbf{4 0 0}$ permeation in parallel with changes in water transport indicating that their effect on permeability is through changes in solvent drag. These findings provide a mechanism which might explain the increase in PEG 400 intestinal permeability in Crohn's disease patients and the increase in intestinal permeability found in patients receiving NSAIDS.
\end{abstract}

The selective ability of the intestinal epithelium to provide a barrier to the absorption of potentially harmful compounds is often referred to as permeability. Abnormal permeability may be important in the pathogenesis and pathophysiology of various diseases such as coeliac disease, ${ }^{12}$ rheumatoid arthritis, ${ }^{3}$ indomethacin-associated enteritis, ${ }^{45}$ and Crohn's disease. ${ }^{6}$

PEG 400 is a water soluble mixture of at least nine different polymers, ranging in molecular weight from 242 to 594 daltons and has an average cross sectional diameter of $0.53 \mathrm{~nm}$. Polyethylene glycol 400 was introduced as an 'ideal' probe for measuring intestinal perme- ability by Chadwick and his colleagues.

We have recently described increased permeability of PEG 400 in patients with Crohn's disease and their clinically healthy relatives. ${ }^{8}$ The mechanisms which are responsible for this increase in PEG 400 permeability, however, are not presently understood. In our previous work we found that passive absorption modulated by solvent drug is the main mechanism of PEG 400 permeation.

The purpose of this study was to examine the possible relationship between prostaglandins and non-steroidal anti-inflammatory drugs on the small intestinal permeation of PEG 400 . We questioned the possible relationship between prostaglandins and PEG 400 absorption because prostaglandins are known to affect sodium and water transport in the small intestine ${ }^{10-12}$ Moreover, an increased concentration of prostaglandins in colonic mucosa is found in patients with ulcerative colitis ${ }^{13}$ and Crohn's disease. ${ }^{14}$

\section{Methods}

\section{ANIMALS}

Non-fasted male fisher 344 rats $(180-300 \mathrm{~g})$ from Charles River Breeding Laboratories were used in all experiments.

\section{SOLUTIONS}

The basic perfusate solution consisted of tracer ${ }^{3}$ H-PEG 400 (New England Nuclear) and 1 mmol/l PEG 400 (Sigma Chemical Company) which were solubilised in a standard Krebsphosphate saline buffer at $\mathrm{pH} 6.5$ with a final osmolarity of $300 \mathrm{~m} 0 \mathrm{sm}$. ${ }^{14} \mathrm{C}$-Inulin was used as a non-absorbable marker. ${ }^{15}$ Acetylsalicylic acid and indomethacin were purchased from Sigma Chemical Company, ethyl alcohol was purchased from Gold Shield Chemical Company, and 16,16 ,-dimethyl prostaglandin $E_{2}$ was purchased from Calbiochem. Each of these was added to the basic perfusate solution as indicated.

\section{IN VIVO PERFUSION}

Using well standardised methods of recycling perfusion previously described, ${ }^{16}$ we cannulated $30 \mathrm{~cm}$ segments of proximal jejunum, starting approximately $5 \mathrm{~cm}$ distal to the ligament of Treitz. Perfusion lasted for three hours. The 30 $\mathrm{ml}$ perfusate was recirculated at $1 \mathrm{ml} / \mathrm{min}$ from a continuously stirred reservoir. Duplicate $100 \mu \mathrm{l}$ samples were taken from the reservoir every 30 
minutes and radioactivity counted in a Beckman LS9000 scintillation counter. ${ }^{14} \mathrm{C}$-Inulin was used as the non-absorbable marker to correct each sample for fluid shifts. The absorption rate of PEG 400 was calculated by measuring its disappearance from the perfusate. Absorption values were calculated per $100 \mathrm{~cm}$ length after standardised stretching and drying of the intestinal segments because this length correlates best with intestinal surface area. ${ }^{17}$ Water absorption or secretion was calculated by the differences between initial and final volume of perfusate and by the differences between initial and final concentrations of ${ }^{14} \mathrm{C}$-Inulin ${ }^{15}$ and expressed as $\mathrm{ml} / 100 \mathrm{~cm}$ of intestinal length per hour.

STATISTICAL ANALYSIS

All values are reported as mean (SEM) and statistical comparisons of control and experimental conditions are made by using ANOVA and Student's $t$ test.

\section{Results}

EFFECT OF 16,16 ,-DIMETHYL PROSTAGLANDIN $E_{2}$ ON JEJUNAL PEG 400 ABSORPTION

Jejunal absorption of PEG 400 was studied after the addition of three different concentrations of 16,16-dimethyl prostaglandin $\mathrm{E}_{2}(0 \cdot 5,1 \cdot 0$, and $1.5 \mu \mathrm{g} / \mathrm{ml}$ ) to the standard Krebs-phosphate saline buffer. The PEG 400 and water absorption were compared with the rats that were perfused with the standard Krebs-phosphate saline buffer without 16,16 ,-dimethyl prostaglandin $E_{2}$. Experimental conditions were similar in both groups. We found that the treatment with 16,16 ,-dimethyl prostaglandin $\mathrm{E}_{2}$ significantly $(\mathrm{p}<0.01)$ decreased PEG 400 and water absorption as compared to the control values of PEG 400 absorption of $13.1(0.5) \mu \mathrm{mol} / 100 \mathrm{~cm} / \mathrm{h}$ and water absorption of $8.9(0.4) \mathrm{ml} / 100 \mathrm{~cm} / \mathrm{h}$. Absorption of PEG 400 of $8 \cdot 3(0 \cdot 5), 8 \cdot 8(0 \cdot 5)$, and $6.0(1.9) \mu \mathrm{mol} / 100 \mathrm{~cm} / \mathrm{h}$ and water absorption of $4 \cdot 8(0 \cdot 2), 4 \cdot 5(0.6)$, and $1 \cdot 2(1 \cdot 2) \mathrm{ml} / 100$ $\mathrm{cm} / \mathrm{h}$ were recorded at 16,16 ,-dimethyl prostaglandin $E_{2}$ concentrations of $0.5,1.0$, and 1.5 $\mathrm{mg} / \mathrm{ml}$ respectively (Fig 1 ). PEG 400 absorption was linearly related to time (three hours) of perfusion in control group $(\mathrm{r}=0.97)$ and in group perfused with $1 \mu \mathrm{g} / \mathrm{ml}$ of 16,16 ,-dimethyl prostaglandin $\mathrm{E}_{2}(\mathrm{r}=0.98)$ (Fig 2).

EFFECT OF ACETYSALICYLIC ACID ON JEJUNAL ABSORPTION OF PEG 400 Influence of acetylsalicylic acid on jejunal absorption of PEG 400 was determined by the addition of 2.5 and $5 \mathrm{mmol} / \mathrm{l}$ acetylsalicylic acid to the basic perfusate solution. Addition of $2 \cdot 5$ $\mathrm{mmol} / \mathrm{l}$ acetylsalicylic acid did not change PEG 400 and water absorption, but addition of 5 $\mathrm{mmol} / \mathrm{l}$ acetylsalicylic acid to the perfusate significantly $(\mathrm{p}<0.01)$ increased PEG 400 absorption to $18 \cdot 1(0.5) \mu \mathrm{mol} / 100 \mathrm{~cm} / \mathrm{h}$ and water absorption to $12 \cdot 1(0.8) \mathrm{ml} / 100 \mathrm{~cm} / \mathrm{h}$, as compared with PEG 400 absorption of $13 \cdot 1(0 \cdot 5)$ $\mu \mathrm{mol} / 100 \mathrm{~cm} / \mathrm{h}$ and water absorption of 8.9

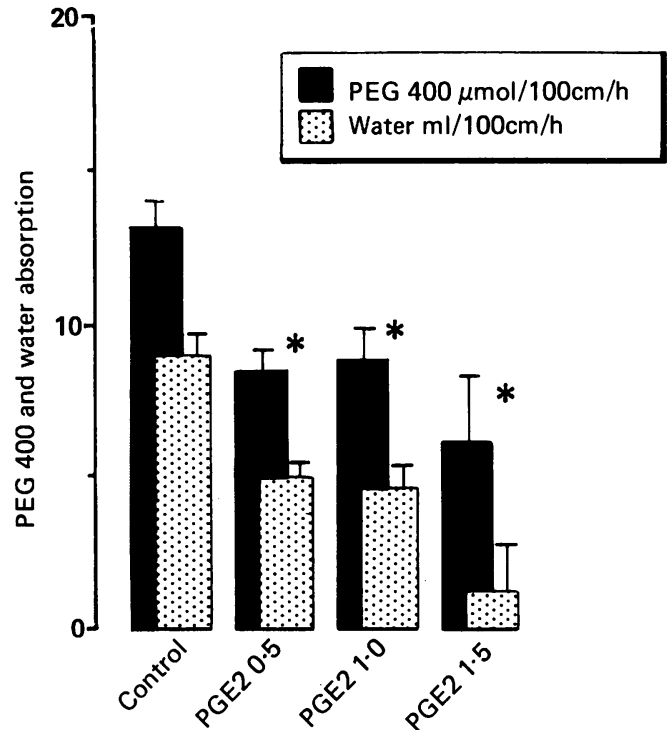

Figure 1: Effect of 16,16-dimethyl prostaglandin $E_{2}(0 \cdot 5$, 1.0 , and $1.5 \mu \mathrm{g} / \mathrm{ml}$ ) on jejunal absorption of $P E G 400$ and water. Three to 11 rats were studied in each group. Each ra provided six separate data points. Perfusate composed of 1 mmolll PEG 400 and Krebs-phosphate saline buffer at $p H$ 6.5 with flow rate of $1 \mathrm{ml} / \mathrm{min}$. Height of the bars indicates mean (SEM). Solid bars represent PEG 400 absorption in umol/100 $\mathrm{cm} / \mathrm{h}$. Open bars represent water absorption in $\mathrm{ml} / 100 \mathrm{~cm} / \mathrm{h} .{ }^{\star}$ denotes a significant $(p<0 \cdot 01)$ difference from control.

$(0.4) \mathrm{ml} / 100 \mathrm{~cm} / \mathrm{h}$ in controls. The results are illustrated in Fig 3. PEG 400 absorption was linearly related to time (three hours) of perfusion with $5 \mathrm{mmol} / 1$ ASA $(\mathrm{r}=0.98)$ (Fig 2$)$.

\section{EFFECT OF INDOMETHACIN ON JEJUNAL PEG 400 ABSORPTION}

The influence of indomethacin (cyclooxygenase inhibitor) on PEG 400 absorption was tested after the addition of three different concentrations of indomethacin $(1 \cdot 0,2 \cdot 5$, and $5 \cdot 0 \mathrm{mmol} / \mathrm{l})$ in the perfusate, which contained $10 \%$ ethyl alcohol in the Krebs-phosphate saline buffer in order to dissolve the indomethacin. The results were compared with the control rats $(n=11)$ perfused with the basic perfusate solution alone, and to additional control rats (three) perfused with $10 \%$ ethyl alcohol solution in the standard Krebs-phosphate saline buffer.

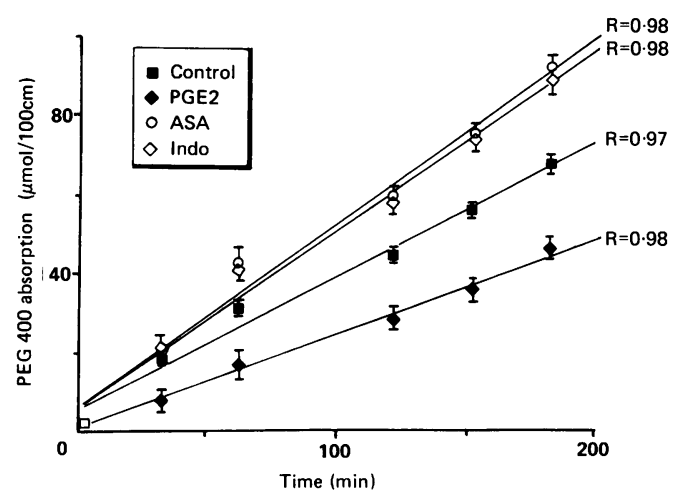

Figure 2: Relationship of perfusion time to PEG 400 absorption in control group of rats, in rats perfused with $1 \mu \mathrm{g} / \mathrm{ml}$ of $P G E_{2}, 5 \mathrm{mmol} / \mathrm{l}$ acetylsalicylic acid $(A S A)$ and $2.5 \mathrm{mmol} / \mathrm{l}$ indomethacin (INDO). The perfusate consisted of $1 \mathrm{mmol} / \mathrm{l}$ PEG 400 and Krebs-phosphate saline buffer at $p H$ 6.5 with flow rate of $1 \mathrm{ml} / \mathrm{min}$. Plotted values are mean (SEM) of three to II different experimental runs. Values were fitted to a linear plot using a linear regression analysis program. 


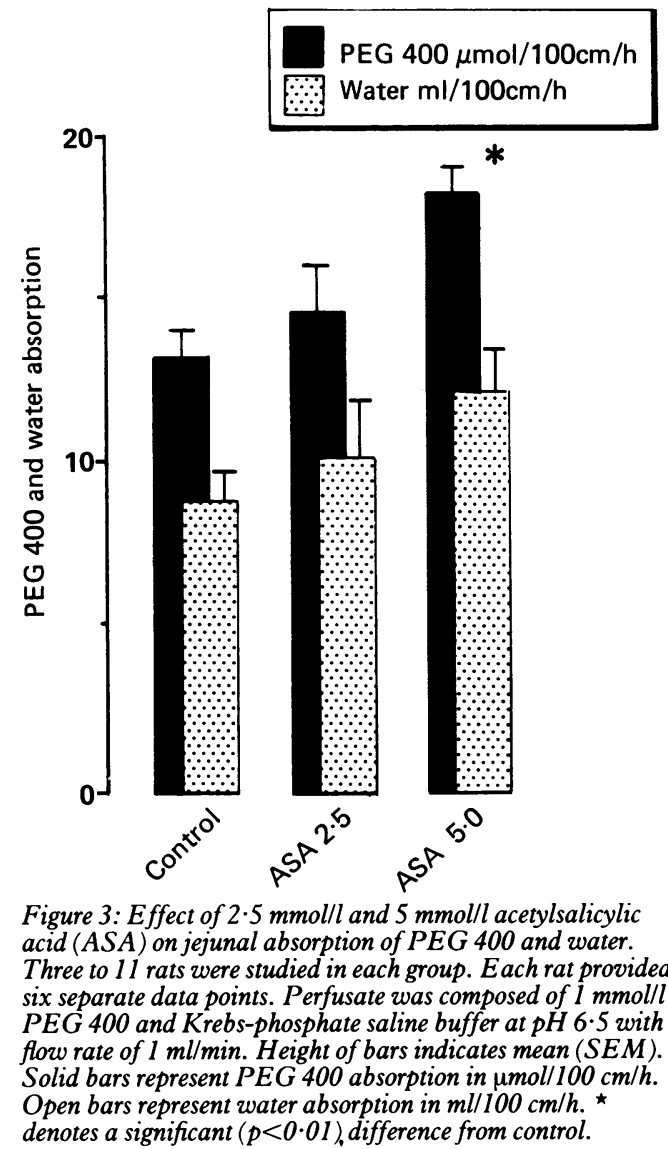

Polyethylene glycol 400 absorption was similar between the control groups (13.1 (0.5) $\mu \mathrm{mol} /$ $100 \mathrm{~cm} / \mathrm{h}$ ), the group perfused with $10 \%$ ethyl alcohol in the basic perfusate solution $(13 \cdot 6(0 \cdot 3)$ $\mu \mathrm{mol} / 100 \mathrm{~cm} / \mathrm{h}$ ), and in group perfused with 1.0 $\mathrm{mmol} / 1$ indomethacin $(11.9(1 \cdot 1) \mu \mathrm{mol} / 100 \mathrm{~cm} /$ $\mathrm{h})$, but was significantly $(\mathrm{p}<0.01)$ increased in the rats perfused with higher $(2 \cdot 5 \mathrm{mmol} / 1$ and $5 \cdot 0$ $\mathrm{mmol} / \mathrm{l})$ concentrations of indomethacin $(17 \cdot 4$ $(0 \cdot 5)$ and $17 \cdot 3(1 \cdot 1) \mu \mathrm{mol} / 100 \mathrm{~cm} / \mathrm{h}$ respectively). Water absorption was similar in control group $(8.9(0.4) \mathrm{ml} / 100 \mathrm{~cm} / \mathrm{h})$, the group perfused with $10 \%$ ethyl alcohol in the standard Krebs-phosphate saline buffer $(9 \cdot 6(1 \cdot 2) \mathrm{ml} / 100 \mathrm{~cm} / \mathrm{h})$, and in group perfused with $1.0 \mathrm{mmol} / \mathrm{l}$ indomethacin $(7 \cdot 1(0 \cdot 8) \mathrm{ml} / 100 \mathrm{~cm} / \mathrm{h})$, but significantly $(\mathrm{p}<0.01)$ higher in the rats perfused with higher $(2.5 \mathrm{mmol} / \mathrm{l}$ and $5.0 \mathrm{mmol} / \mathrm{l})$ concentrations of indomethacin $(11.9(0.5)$ and $11.6(0.8) \mathrm{ml} / 100$ $\mathrm{cm} / \mathrm{h}$ respectively). The results are illustrated in Figure 4. No differences were found in PEG 400 and water absorption between rats perfused with 2.5 and $5.0 \mathrm{mmol} / \mathrm{l}$ of indomethacin. PEG 400 absorption was linearly related to time (three hours) of perfusion with $2.5 \mathrm{mmol} / \mathrm{l}$ indometha$\operatorname{cin}(r=0.98)($ Fig 2$)$.

EFFECT OF ACETYSALICYLIC ACID WITH $16,16,-$ DIMETHYL PROSTAGLANDIN $E_{2}$ ON JEJUNAL ABSORPTION OF PEG 400

Influence of acetysalicylic acid with the simultaneous addition of 16,16,-dimethyl prostaglandin $E_{2}$ on jejunal absorption of PEG 400 was determined by the addition of $5 \mathrm{mmol} / \mathrm{l}$ acetyl-

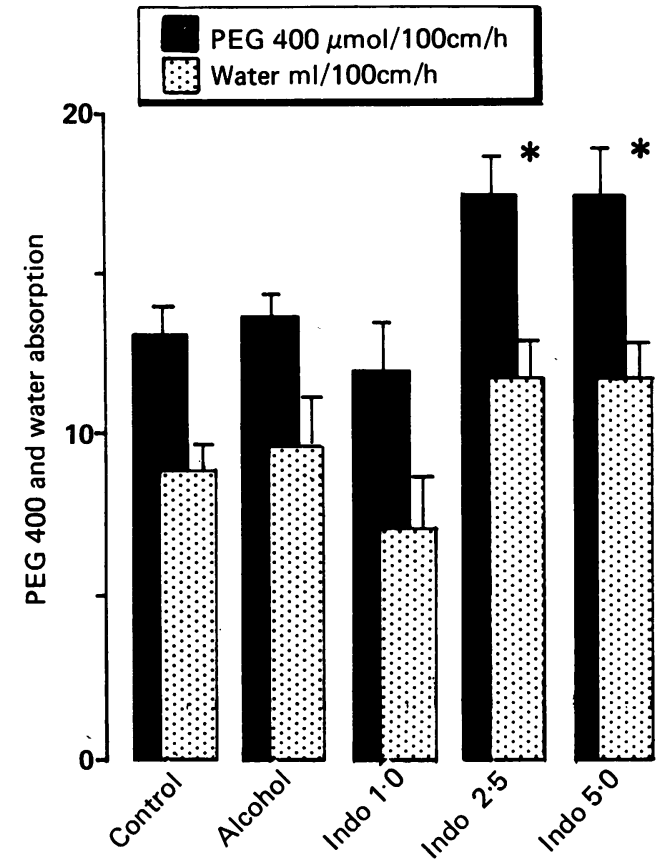

Figure 4: Effect of 1.0,2.5 and 5.0 mmoll of indomethacin (INDO) and 10\% alcohol (alcohol) on jejunal absorption of $P E G 400$ and water. Three to 11 rats were studied in each group. Each rat provided six separate data points. Perfusate composed of 1 mmol/l PEG 400 and Krebs-phosphate saline buffer at $\mathrm{pH} 6.5$ with flow rate of $1 \mathrm{ml} / \mathrm{min}$. Height of the bars indicates mean (SEM). Solid bars represent PEG 400 indicates mean $(S E M)$. Sold bars represent $P E G 400$ absorption in $\mathrm{ml} / 100 \mathrm{~cm} / \mathrm{h} .{ }^{\star}$ denotes a significant $(p<0.01)$ difference from control.

salicylic acid with $1 \mu \mathrm{g} / \mathrm{ml} \quad 16,16$,-dimethyl $\mathrm{PGE}_{2}$ to the basic perfusate solution.

We found that addition of acetylsalicylic acid together with 16,16,-dimethyl prostaglandin $E_{2}$ significantly $(p<0.01)$ decreased PEG 400 and water absorption compared with the control (Table). There were no significant differences in PEG 400 and water absorption between rats perfused with both acetylsalicylic acid and 16,16 ,-dimethyl prostaglandin $E_{2}$ and rats perfused with 16,16 ,-dimethyl prostaglandin $E_{2}$ alone.

\section{EFFECT OF INDOMETHACIN TOGETHER} WITH $16,16,-$-DIMETHYL PROSTAGLANDIN $E_{2}$ ON JEJUNAL PEG 400 ABSORPTION We tested jejunal absorption of PEG 400 after the simultaneous addition of $2.5 \mathrm{mmol} / \mathrm{l}$ indomethacin with $1 \mu \mathrm{g} / \mathrm{ml}$ of 16,16 ,-dimethyl

TABLE Effect of $P G E_{2}$ and cyclooxygenase inhibitors on TABLE 400 and water absorption

\begin{tabular}{|c|c|c|c|}
\hline Addition & Rats $(n)$ & $\begin{array}{l}\text { PEG400 } \\
\text { absorption } \\
\mu \text { mol/100 } \mathrm{cm} / \mathrm{h}\end{array}$ & $\begin{array}{l}\text { Water } \\
\text { absorption } \\
\mathrm{ml} / 100 \mathrm{~cm} / \mathrm{h}\end{array}$ \\
\hline \multirow{7}{*}{$\begin{array}{l}\text { Control } \\
\text { PGE }_{2} 1 \mu \mathrm{g} / \mathrm{ml} \\
\text { Aspirin } 5 \mathrm{mmol} / \mathrm{l} \text { (ASA) } \\
\text { Indomethacin } 2.5 \mathrm{mmol} / \mathrm{l} \\
\text { (INDO) } \\
\text { ASA } 5 \mathrm{mmol} / 1 \text { and } \mathrm{PGE}_{2} \\
1 \mu \mathrm{ml} \\
\text { INDO } 2.5 \mathrm{mmol} / \mathrm{l} \text { and } \\
\text { PGE }_{2} 1 \mu \mathrm{g} / \mathrm{ml}\end{array}$} & 11 & $13 \cdot 1(0 \cdot 5)$ & $8.9(0.4$ \\
\hline & 3 & $8.8(0.5)^{\star}$ & $4.5(0 \cdot 6)^{\star}$ \\
\hline & 4 & $18 \cdot 1(0.5)^{\star}$ & $12 \cdot 1(0 \cdot 8)^{\star}$ \\
\hline & & & \\
\hline & 4 & $17 \cdot 4(0 \cdot 5)^{\star}$ & $11.9(0.6)^{\star}$ \\
\hline & 3 & $8.8(0 \cdot 3)^{\star}$ & $5 \cdot 1(0.5)^{\star}$ \\
\hline & 4 & $8.3(0 \cdot 3)^{\star}$ & $3.5(0.3)^{\star}$ \\
\hline
\end{tabular}

^ Denotes a significant $(\mathrm{p}<0.01)$ difference from control

absorption. Values are mean (SEM) of the six data points per rat. 
prostaglandin $\mathrm{E}_{2}$ in $10 \%$ ethyl alcohol solution in the standard Krebs-phosphate saline buffer.

Addition of both indomethacin and 16,16,dimethyl prostaglandin $\mathrm{E}_{2}$ significantly $(\mathrm{p}<0.01)$ decreased PEG 400 and water absorption compared to the control values (Table). There were no significant differences in PEG 400 and water absorption between rats perfused with both indomethacin with 16,16 ,-dimethyl prostaglandin $E_{2}$ and rats perfused by 16,16,-dimethyl prostaglandin $\mathrm{E}_{2}$ alone.

\section{Discussion}

We studied the influence of exogenous 16,16 ,dimethyl prostaglandin $\mathrm{E}_{2}\left(\mathrm{PGE}_{2}\right)$ and cyclooxygenase inhibitors on the intestinal absorption of PEG 400 because of the known influence of prostaglandins on water transport and because of the documented increase in prostaglandins in the lumen and in the mucosa of patients with inflammatory bowel disease. ${ }^{13}$ We have previously established that the rate and the direction of water transport are major factors which regulate and modulate the intestinal permeation of PEG 400 and PEG $900 .^{918}$ The present data show that endogenous and exogenous prostaglandins are also potent regulators of PEG 400 permeation through regulation of net water flow.

In the present study we found that the addition of $\mathrm{PGE}_{2}$ in concentrations of $0.5,1.0$, and $1.5 \mu \mathrm{g} / \mathrm{ml}$ to the perfusate resulted in parallel decrease in both PEG 400 and water absorption (Fig 1). When we added the cyclooxygenase inhibitor ASA in concentration of $5 \mathrm{mmol} / \mathrm{l}$ or indomethacin in concentrations of 2.5 and 5.0 $\mathrm{mmol} / \mathrm{l}$ the absorption of PEG 400 and water increased (Figs 3, 4). The increase in transport was reversed by the simultaneous addition to the perfusate of exogenous $\mathrm{PGE}_{2}$ (Table). These experiments clearly show that $\mathrm{PGE}_{2}, \mathrm{ASA}$ and indomethacin change PEG 400 permeation in parallel with water absorption. We concluded that ASA and indomethacin influenced PEG 400 and water absorption by blocking the cyclooxygenase pathway and thereby decreasing endogenous synthesis of prostanoids.

Our observations are in concert with the findings of Bjarnson et al, who showed that NSAID increased permeability of ${ }^{51} \mathrm{Cr}$-EDTA. Our findings provide an explanation and a mechanism which could account for Bjarnson's results. By giving NSAID to the patients with rheumatologic disorders or to normal volunteers, the endogenous synthesis of prostaglandins was decreased by blocking the cyclooxygenase enzyme system and intestinal permeability of ${ }^{51} \mathrm{Cr}$-EDTA and water increased.

At this point, we can only speculate as to the mechanisms by which endogenous or exogenous prostaglandins inhibit water absorption and PEG 400 permeation. Our previous data clearly indicate that PEG 400 and PEG 900 absorption is modulated by solvent drag. As net water absorption increases, net PEG 400 and PEG 900 permeation follow. ${ }^{918}$ PEG 400 penetration of the intestinal barrier is mediated by two separate forces - simple passive diffusion along its concentration gradient and solvent drag or convection. In the small intestine we found that $43 \%$ of the total transport was the result of diffusion while $57 \%$ of the transport was mediated by convection. ${ }^{9}$ In the colon, only $14 \cdot 3 \%$ of total PEG 400 transport is caused by passive diffusion while $85 \cdot 7 \%$ was due to convection (submitted data). Thus permeability changes after NSAID or ASA administration are probably secondary to changes in water flux which in turn are regulated by the concentration of prostaglandins in the mucosa.

There are data which suggest that the inhibitory effect of prostaglandins on net water absorption may be mediated, at least in part, by prostaglandin effect on sodium and chloride transport. Sernka and coworkers showed that $\mathrm{PGE}_{2}$ inhibited sodium absorption and stimulated chloride secretion in vitro. ${ }^{19}$ These changes would result in decreased net water absorption.

It has been shown that $\mathrm{PGE}_{2}$ stimulates mucosal adenylate cyclase through cyclic $3^{\prime} 5^{\prime}$ $\mathrm{AMP}$ as a mediator, similar to cholera exotoxin ${ }^{20}$ and cyclic $3^{\prime}$ ' '-AMP stimulates active secretion of chloride and inhibits the active absorption of sodium. ${ }^{21}$ Therefore, a possible mechanism by which prostaglandins may inhibit water and PEG 400 absorption is by their effect of stimulating mucosal cyclic $3^{\prime} 5^{\prime}$-AMP. In addition, according to Brunsson et $a l^{22} \mathrm{PGE}_{2}$ acts on intestinal fluid transport by both neural and nonneural mechanisms. Neural response to $\mathrm{PGE}_{2}$ is not mediated through cAMP, but may decrease water absorption via hormonally independent mechanisms.

Cyclic AMP may also have a specific role in the orientation of tight junctional intramembranous strands, ${ }^{23}$ thereby perhaps affecting paracellular transport of larger molecules such as PEG 400.

Water transport occurs secondary to osmotic forces, and is influenced by active sodium, glucose and amino acid absorption. According to recent reports some hydrophilic electrically neutral molecules are absorbed by osmotic forces, mostly through the paracellular pathway.$^{24}$ It has been shown that sodium coupled active transport increases fluid absorption through intercellular junctions. ${ }^{25}$ These physiological changes correlate well with the morphological changes seen on light microscopy, transmission electron microscopy, and freeze fracture techniques which showed dilatation of tight junction after perfusion with glucose, alanine or leucine.$^{26}$ In addition it has been shown that junctional dilatation is an active process involving contractile proteins of the terminal web and can be affected by cAMP. ${ }^{27}$ Therefore prostaglandins can be modulators of junctional permeability by acting through cAMP. Decrease in PEG 400 and water absorption by $\mathrm{PGE}_{2}$ in the present work correlate well with the results obtained by Duffey et al. ${ }^{23}$ They showed in Necturus gall bladder epithelium that cyclic AMP increased the resistance to passive ion flow through the paracellular pathway by aggregation of microfilaments in regions adjacent to the tight junctions.

In summary our studies show that 16,16 ,dimethyl prostaglandin $E_{2}$ decreased PEG 400 permeability in parallel with decreasing water absorption. Non-steroidal anti-inflammatory drugs increased PEG 400 and water absorption probably by decreasing endogenous mucosal 
prostanoid synthesis. We conclude that prostaglandins are potent regulators of PEG 400 intestinal permeability through their direct and indirect effects on water transport. As permeability changes are potentially related to the pathogenesis of Crohn's disease ${ }^{28}$ these observations are important in clarifying our understanding of inflammatory bowel disease.

This study was supported by the Goldsmith Family Foundation and by Grant \#AG-2627 from the National Institutes on Aging.

1 Bjarnason I, Peters TJ, Veal N. A persistent defect in intestinal permeability in coeliac disease demonstrated by a "Crlabelled EDTA absorption test. Lancet 1983; ii: 323-5.

2 Hamilton I, Cobden I, Rothwell J, Axon ATR. Intestinal permeability in coeliac disease: the response to gluten withdrawal and single-dose gluten challenge. Gut 1982; 23: 202-10.

3 Jenkins RT, Rooney PJ, Jones DB, Bienenstock J, Goodacre RL. Increased intestinal permeability in patients with rheumatoid arthritis: a side-effect of oral nonsteroidal antiinflammatory drug therapy? $\mathrm{Br} \mathcal{F}$ Rheumatol 1987; 26: 103 7.

4 Bjarnason I, Williams P, Smethurst P, Peters TJ, Levi AJ. Effect of non-steroidal anti-inflammatory drugs and prostaglandins on the permeability of the human small intestine. Gut 1986; 27: 1292-7.

5 Bjarnason I, Zanelli G, Smith T, et al. Nonsteroidal antiinflammatory drug-induced intestinal inflammation in humans. Gastroenterology 1987; 93: 480-9.

6 Jenkins RT, Goodacre RL, Rooney PJ, Bienenstock J, Sivakumaran T, Walker WHC. Studies of intestinal permeability in inflammatory diseases using polyethylene glyco 400. Clin Biochem 1986; 19: 298-302.

7 Chadwick VS, Phillips SF, Hofmann AF. Measurements of intestinal permeability using low molecular weight polyethylene glycols (PEG 400). Gastroenterology 1977; 73: 241-6.

8 Hollander D, Vadheim CM, Brettholz E, Petersen GM, Delahunty $T$, Rotter JI. Increased intestinal permeability in Delah 1 , Roter, JI. Increased intestinal permeability in patients with Crohn's

9 Krugliak P, Hollander D, Tran D, Dadufalza VD, Katz KD, Le K. Mechanisms of polyethylene glycol 400 permeability in perfused rat intestine Gastroenterology $1989 ; 97: 1164-70$.

10 Pierce NF, Carpenter CCJ, Elliott HL, Greenough WB Effects of prostaglandins, theophylline, and cholera exotoxin upon transmucosal water and electrolyte movement in the canine jejunum. Gastroenterology 1971; 60: 22-32.

11 Moriarty KJ, O'Grady J, Rolston DDK, Kelly MJ, Clark ML.
Effect of prostacyclin $\left(\mathrm{PGI}_{2}\right)$ on water and solute transport in the human jejunum. Gut 1986; 27: 158-63.

12 Matuchansky C, Bernier JJ. Effect of prostaglandin $E_{1}$ on glucose, water, and electrolyte absorption in the human jejunum. Gastroenterology 1973; 64: 1111-8.

13 Rampton DS, Sladen GE. Relationship between rectal mucosal prostaglandin production and water and electrolyte transport in ulcerative colitis. Digestion $1984 ; 30$ : 13-22.

14 Hawkey CJ, Fanny K, Rachmilewitz D. Imbalance of prostacyclin and thromboxane synthesis in Crohn's disease. Gut 1983; 24: 881-5.

15 Miller DL, Schedl HP. Total recovery studies of nonabsorbable indicators in the rat small intestine. Gastroenterology 1970; 58: 40-6.

16 Hollander D. Intestinal absorption of vitamins A, E, D and K f L ab Clin Med 1981; 97: 449-62.

17 Meshkinpour H, Smith M, Hollander D. Influence of aging on the surface area of the small intestine in the rat. $E x$ Gerontol 1981; 16: 399-404

18 Hollander D, Koyama S, Dadufalza V, Tran DQ, Krugliak P, Ma T, Ling K-Y. Polyethylene glycol-900 permeability of rat intestinal and colonic segments in-vivo and brush border
membrane vesicle in-vitro. $\mathcal{F}$ Lab Clin Med 1989; 113: 50515 .

19 Sernka TJ, Rood RP, Mah MY, Tseng CH. Antiabsorptive effects of 16,16,-dimethyl prostaglandin $E_{2}$ in isolated rat colon. Prostaglandins 1982; 23: 41 1-26.

20 Kimberg DV, Field M, Johnson J, Henderson A, Gershon E. Stimulation of intestinal mucosal adenyl cyclase by choler enterotoxin and prostaglandins. F Clin Invest 1971; 50: 1218-30.

21 Field M, Plotkin G, Silen W. Cyclic AMP induced secretion of chloride by rabbit ileum in vitro. Gastroenterology 1968; 54: 1233.

22 Brunsson I, Sjoqvist A, Jodal M, Lundgren O. Mechanisms underlying the small intestinal fluid secretion caused by arachidonic acid, prostaglandin $\mathrm{E}_{1}$ and prostaglandin $\mathrm{E}_{2}$ in arachidonic acid, prostaglandin $E_{1}$ and prostaglandin
the rat in vivo. Acta Physiol Scand 1987; 130: 633-42.

23 Duffey ME, Hainau B, Ho S, Bentzel CJ. Regulation of epithelia tight junction permeability by cyclic AMP. Nature 1981; 294: 451-3.

24 Pappenheimer JR, Reiss KZ. Contribution of solvent drag through intercellular junctions to absorption of nutrients by the small intestine of the rat. $7 \mathrm{Membr}$ Biol 1987; 100: 123 36.

25 Pappenheimer JR. Physiological regulation of transepithelial impedance in the intestinal mucosa of rats and hamsters. $\mathcal{F}$ Membr Biol 1987; 100: 137-48.

26 Madara JL, Pappenheimer JR. Structural basis for physiological regulation of paracellular pathways in intestinal epithelia. f Membr Biol 1987; 100: 149-64.

27 Madara JL. Tight junction dynamics: is paracellular transport regulated? Cell 1988; 53: 497-8.

28 Hollander D. Crohn's disease - a permeability disorder of the tight junction? Gut 1988; 29: 1621-4. 